\title{
CATALYTIC HYDROGENOLYSIS OF NATIVE AND ORGANOSOLV LIGNINS OF ASPEN WOOD TO LIQUID PRODUCTS IN SUPERCRITICAL ETHANOL MEDIUM
}

\section{$\underline{\text { B.N. Kuznetsov }}^{1,2}$, V.I. Sharypov ${ }^{1}$, S.V. Baryshnikov ${ }^{1}$, A.V. Miroshnikova ${ }^{1}$, V.A. Yakovlev ${ }^{3}$,} A.B. Lavrenov ${ }^{3}$, L. Djakovitch ${ }^{4}$

${ }^{I}$ Institute of Chemistry and Chemical Technology SB RAS, FRC KSC SB RAS, Krasnoyarsk,Russia,bnk@icct.ru; inm@icct.ru

${ }^{2}$ Siberian Federal University, Krasnoyarsk, Russia

${ }^{3}$ Boreskov Institute of Catalysis SB RAS, Novosibirsk, Russia

${ }^{4}$ IRCELYON, Lyon, F-69626 Villeurbanne Cedex, France

\begin{abstract}
Catalytic hydrogenolysis in the medium of supercritical organic solvents is a promising way of wood lignins depolymerization into liquid products.

In this study, for the first time, the catalytic properties of bifunctional catalysts $\mathrm{Ru} / \mathrm{C}$, $\mathrm{Pt} / \mathrm{ZrO}_{2}, \mathrm{NiCuMo} / \mathrm{SiO}_{2}$, containing nanosized metal particles on acidic supports are compared in the processes of aspen wood and ethanol lignin hydrogenolysis in supercritical ethanol.

The most active catalysts are $\mathrm{Ru} / \mathrm{C}$ and $\mathrm{Pt} / \mathrm{ZrO}_{2}$ which provide the high conversion of wood (to $78 \mathrm{wt} \%$ ), significant yield of liquid products (to $50.6 \mathrm{wt} \%$ ) and low yield of solid rest (to 22 wt\%) at temperature $250{ }^{\circ} \mathrm{C}$ and $\mathrm{H}_{2}$ pressure $9 \mathrm{MPa}$. These catalysts increase the yield of monomeric compounds in liquid products from $9.5 \%$ to $42.9 \%$ on mass of lignin.

GC-MS analysis shows that alkyl derivatives of methoxyphenols (mainly propyl syringol and propyl quaiacol) are dominated in liquid products. Solid products of aspen wood catalytic hydrogenolysis contain mainly cellulose (to $82.2 \mathrm{wt} \%$ ). Therefore, the catalytic hydrogenolysis in supercritical ethanol in the presence of by functional catalysts $\mathrm{Ru} / \mathrm{C}$ and $\mathrm{Pt} / \mathrm{ZrO}_{2}$ allows to fractionate the aspen wood biomass on cellulose and liquid products enriched with propyl siringol and propyl quaiacol.
\end{abstract}

In catalytic hydrogenolysis of ethanol lignin the yield of alkyl derivatives of methoxyphenols is lower compared to wood. This is probably due to the reduced content of reactive $\beta-\mathrm{O}-4$ bonds in the structure of ethanol lignin compared to native lignin of aspen wood. As follows from the results obtained, native lignin of wood is easier depolymerized to monomeric compounds in the process of catalytic hydrogenolysis than ethanol lignin, isolated from wood.

According to GPC data, the catalysts shift to the region of lower molecular mass the molecular mass distribution of liquid products of aspen wood and ethanol lignin hydrogenolysis.

Keywords: aspen wood, hydrogenolysis, catalysts, bioliquids. 


\section{Introduction}

Wood lignin, being a renewable source for producing valuable phenolic and aromatic hydrocarbons, remains a little used raw material [1-5]. The hydrolysis industry produces condensed lignin as a byproduct which is difficult to process into valuable chemicals. One of the promising method of lignin isolation is the extraction of lignocellulosic materials with organic solvent or its mixtures with water $[6,7]$. The resulting organosolv lignins do not contain sulfur and have a higher reactivity compared to traditional technical lignins. However, when organosolv lignins are isolated the undesirable polymerization processes can occur, leading to a decrease in their yield and reactivity [8]. These circumstances make it urgent to develop methods of lignin depolymerization which eliminate the additional stage of its isolation from lignocellulosic material.

Catalytic hydrogenolysis of lignocellulosic biomass in the medium of supercritical organic solvents allows to combine the stages of lignin isolation and its catalytic depolymerization [9-11].

In particular, the influence of acid high silica zeolites catalysts on the depolymerization of aspen wood in supercritical ethanol medium at $270{ }^{\circ} \mathrm{C}$ was studied [12]. The most active catalyst with ratio $\mathrm{Si} / \mathrm{Al}=30$ produces $86 \mathrm{wt} \%$ of liquid products at $270{ }^{\circ} \mathrm{C}$ and pressure $6.4 \mathrm{MPa}$. They are mainly represented by compounds formed from wood polysaccharides: 5-HMF, furfural, levulinic acid, ethyl esters etc. The catalyst $\mathrm{NiCuMo} / \mathrm{SiO}_{2}$ gives the high yield of liquid products (near 90 $\mathrm{wt} \%$ ) in the depolymerization of aspen ethanol lignin in supercritical ethanol at $300{ }^{\circ} \mathrm{C}$ and 11.6 MPa [13]. This catalyst reduces the content of phenol and benzene derivatives and increases the content of esters, aldehydes and ketons in hexane soluble liquid products.

In the presence of hydrogen or hydrogen-donor compounds, an increase in the yield of liquid products of lignin catalytic depolymerization can be expected due to intensification of the reactions of $\mathrm{C}-\mathrm{O}$ and $\mathrm{C}-\mathrm{C}$ bonds rupture. The reductive depolymerization of lignocellulosic biomass is carried out in organic solvents in the presence of metal-containing catalysts $(\mathrm{Pd} / \mathrm{C}, \mathrm{Ru} / \mathrm{C}, \mathrm{Ni} / \mathrm{C}$, $\mathrm{Ni} / \mathrm{Al}_{2} \mathrm{O}_{3}$ etc) [14-16]. In the processes of biomass hydrogenolysis the low molecular weight soluble products are formed from hemicelluloses and lignin, while cellulose remains as a solid residue. The lower aliphatic alcohols with hydrogen donor properties are usually used as organic solvents. In the process of catalytic hydrogenolysis of biomass they extract the products of biomass depolymerization, alkylate and reduce the reactive intermediates, preventing their condensation [17]. Ethanol is a promising solvent, which can be obtained in the required quantities using existing industrial technologies [18].

The use of solid bifunctional catalysts on the basis of platinum metals and less expensive metals $(\mathrm{Ni}, \mathrm{Mo})$ on oxide $\left(\mathrm{Al}_{2} \mathrm{O}_{3}, \mathrm{SiO}_{2}\right)$ and carbon supports allows to intensify the depolymerization of lignin and to increase the yield of monomeric phenol derivatives [19-24]. Catalysts $\mathrm{NiCu} / \mathrm{SiO}_{2}$ and $\mathrm{NiCuMo} / \mathrm{SiO}_{2}$ were developed for the process of bio-oil 
hydrodeoxygenation [25]. These catalysts were successfully used for depolymerization of aspen aceton lignin in the medium of supercritical butanol [26, 27]. The most active catalyst $\mathrm{NiCuMo} / \mathrm{SiO}_{2}$ increases by 2.4 times the yield of liquid products compared to non-catalytic process. The catalyst $\mathrm{Ru} / \mathrm{C}$ is active in the processes of hydrogenolysis of birch ethanol lignin [28, 29], abies wood and ethanol lignin [30] and catalyst $\mathrm{Ni}-\mathrm{Cu} / \mathrm{ZrO}_{2}-$ in the process of biodiesel and anisole hydrodeoxygenation [31].

In the present study, for the first time, the catalytic properties of bifunctional catalysts $\mathrm{Ru} / \mathrm{C}$, $\mathrm{Pt} / \mathrm{ZrO}_{2}, \mathrm{NiCuMo} / \mathrm{SiO}_{2}$, containing nanosized metal particles on acidic supports are compared in the processes of aspen wood and ethanol lignin hydrogenolysis in supercritical ethanol medium. Optimal process conditions providing the high yield of monomeric derivatives of phenol have been established.

\section{Experimental}

\subsection{Initial wood materials}

The air-dry sawdust (fraction 2-5 mm) of aspen wood (Populus tremula) with chemical composition (wt\%): cellulose -46.3 , lignin -20.4 , hemicellulose -24.1 , ash -0.5 and elemental composition (wt\%): $\mathrm{C}-49.9, \mathrm{H}-6.1, \mathrm{O}-44.0$ was used in the experiments.

Ethanol lignin was isolated from aspen wood according to procedure described in [32] by extraction of wood fraction $\leq 1 \mathrm{~mm}$ with $60 \%$ ethanol at $190{ }^{\circ} \mathrm{C}$ during $3 \mathrm{~h}$. The soluble ethanol lignin was precipitated by cold water $\left(-4^{\circ} \mathrm{C}\right)$, separated from solution by filtration and dried at $50{ }^{\circ} \mathrm{C}$ until constant weight. The yield of ethanol lignin is $12.5 \mathrm{wt} \%$, what corresponds to $56 \mathrm{wt} \%$ from lignin content in aspen wood.

\subsection{Catalysts}

Catalyst $\mathrm{NiCuMo} / \mathrm{SiO}_{2}$ was prepared by the sol - gel method described in [33]. Appropriate amounts of commercial nickel (II) carbonate basic hydrate, copper (II) carbonate basic and molybdenum (VI) oxide were mixed with the required amount of water solution of ammonia (25\% of $\mathrm{NH}_{3}$ ) and bidistilled water under constant stirring. Afterwards, the obtained suspension was filtered, left to dry in air overnight at $120{ }^{\circ} \mathrm{C}$, and then calcined at $400{ }^{\circ} \mathrm{C}$ for 4 hours. The resulting mixed nickel-copper-molybdenum oxide systems were fractionated to $2-5 \mathrm{~mm}$. The prepared granules were impregnated with ethyl silicate (with $\mathrm{SiO}_{2}$ content of $32 \mathrm{wt} . \%$ ), followed by drying of the samples at $120{ }^{\circ} \mathrm{C}$ for 12 hours and calcination at $500{ }^{\circ} \mathrm{C}$ for 2 hours. Then, the samples were reduced in a hydrogen flow at $500{ }^{\circ} \mathrm{C}$ in a quartz reactor, kept at this temperature for 1 hour. Then they were cooled and passivated with a mixture of $\mathrm{O}_{2}(2 \%) / \mathrm{N}_{2}$. The resulting catalyst contains 
(wt $\%$ ): $\mathrm{Ni}-49, \mathrm{Cu}-6, \mathrm{Mo}-5$. The surface area of the catalyst is $109 \mathrm{~m}^{2} / \mathrm{g}$, the pore volume is $0.23 \mathrm{~cm}^{3} / \mathrm{g}$, the average size of the metal particles is $10 \mathrm{~nm}[33]$.

Catalyst $\mathrm{Ru} / \mathrm{C}$ was prepared using a graphite-like carbon support Sibunit (fraction 56-96 $\mu \mathrm{m})$ according to the procedure [34]. The support was oxidized with moist air for 4 hours at $450{ }^{\circ} \mathrm{C}$. Ruthenium was deposited by impregnating the carbon support in terms of moisture capacity with an aqueous solution of ruthenium nitrazyl nitrate $\mathrm{Ru}(\mathrm{NO})\left(\mathrm{NO}_{3}\right)_{3}$. The active component was reduced in a stream of hydrogen [35]. The surface area of the $\mathrm{Ru} / \mathrm{C}$ catalyst is $371 \mathrm{~m}^{2} / \mathrm{g}$, the pore volume is $0.53 \mathrm{~cm}^{3} / \mathrm{g}$, the average particle size of $\mathrm{Ru}$ is $1 \mathrm{~nm}$, and $\mathrm{pH}=6.09$ (at the point of zero charge) [28].

Catalyst $\mathrm{Pt} / \mathrm{ZrO}_{2}$ was prepared according to the procedure [36]. Zirconium hydroxide was obtained by slow precipitation from an aqueous solution of $1 \mathrm{M} \mathrm{ZrO}\left(\mathrm{NO}_{3}\right)_{2}$ with an excess of $\mathrm{NH}_{4} \mathrm{OH}$. The precipitate was dried at $120{ }^{\circ} \mathrm{C}$ and treated with a $2 \mathrm{M}$ sulfuric acid solution. The resulting sulfated material was dried at $120^{\circ} \mathrm{C}$ and calcined at $650{ }^{\circ} \mathrm{C}$ in an air stream. To prepare a bifunctional catalyst, the support was impregnated with a solution of $\mathrm{H}_{2} \mathrm{PtCl}_{6}$. The sample was dried at $120{ }^{\circ} \mathrm{C}$ and calcined at $450{ }^{\circ} \mathrm{C}$ in a stream of air. The $\mathrm{Pt} / \mathrm{ZrO}_{2}$ catalyst contains $\mathrm{Pt}-1.0$ wt.\%, $\mathrm{SO}_{4}{ }^{-2}-5.9$ wt. $\%$, the rest is $\mathrm{ZrO}_{2}$. The surface area of the catalyst is $110 \mathrm{~m}^{2} / \mathrm{g}$, and the pore volume is $0.09 \mathrm{~cm}^{3} / \mathrm{g}$, the particle size of Pt varies from 1 to $2 \mathrm{~nm}$.

\subsection{Hydrogenolysis of aspen wood and ethanol lignin}

The processes of wood sawdust and ethanol lignin hydrogenolysis in supercritical ethanol were carried out in $300 \mathrm{ml}$ autoclave (ChemRe SYStem R-201, the Republic of Korea) with stirring $(800 \mathrm{rpm})$. Substrate $(5.0 \mathrm{~g})$, catalyst $(0.5 \mathrm{~g})$ and of ethanol $(50 \mathrm{ml})$ were charged into the reactor. The air was removed from the autoclave by purging it with argon. Afterwards, hydrogen was supplied with an initial pressure of $4 \mathrm{MPa}$ and the autoclave was heated at a rate of $10{ }^{\circ} \mathrm{C} / \mathrm{min}$ to $250{ }^{\circ} \mathrm{C}$. The duration of heat treatment at the final temperature was $3 \mathrm{~h}$.

The scheme of the study of aspen wood and ethanol lignin hydrogenolysis and products analysis is presented in Fig. 1. 


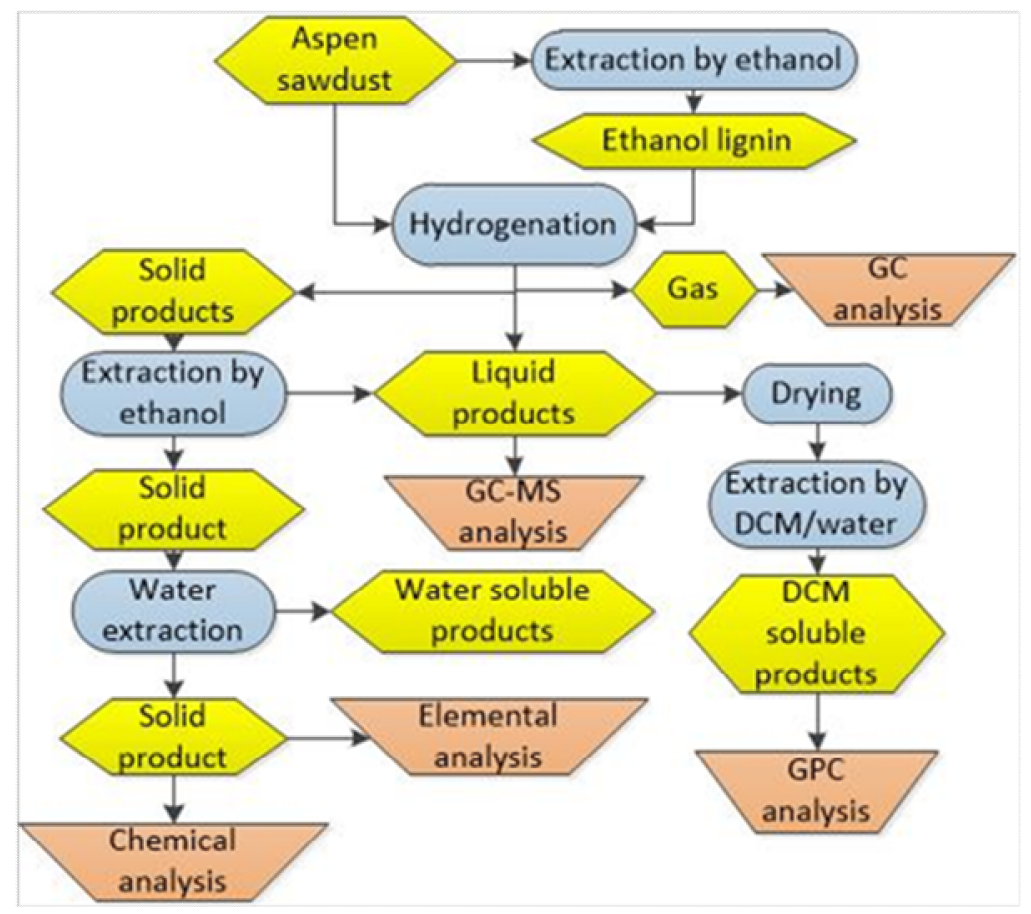

Fig. 1. Scheme of the study of aspen wood and ethanol-lignin hydrogenolysis and products analysis.

At the end of the experiment, the autoclave was cooled to room temperature, the volume of gaseous products was determined and their analysis was performed by gas chromatography. Liquid and solid products were removed from the autoclave by washing with ethanol. The resulting mixture of liquid and solid products was separated by filtration. The solid residue was extracted with ethanol in a Soxhlet apparatus. The ethanol extract was combined with the filtrate, an aliquot was taken from the resulting mixture for analysis by gas chromatography-mass spectrometry (GCMS). The yield of liquid products $\left(\alpha_{1}\right.$, wt.\%) was calculated according to Eq. (1):

$\alpha_{1}=\frac{m_{l}(g)}{m_{w}(g)} \times 100 \%$,

Where: $\mathrm{m}_{\mathrm{l}}$ is the mass of liquid products $(\mathrm{g}), \mathrm{m}_{\mathrm{w}}$ is the mass of the wood $(\mathrm{g})$.

In the experiments with wood, the solid residue was extracted with water in a Soxhlet apparatus and was dried at $80{ }^{\circ} \mathrm{C}$ to constant weight. The yield of water soluble products $\left(\alpha_{2}\right.$, wt. $\left.\%\right)$ was calculated according to Eq. (2):

$\alpha_{2}=\frac{m_{s r 1}(g)-m_{s r 2}(g)}{m_{w}(g)} \times 100 \%$,

Where: $\mathrm{m}_{\mathrm{sr} 1}$ is the mass of the solid residue after extraction with ethanol $(\mathrm{g}), \mathrm{m}_{\mathrm{sr} 2}$ is the mass of the solid residue after extraction with water $(\mathrm{g})$.

The yield of solid products $\left(\alpha_{3}\right.$, wt.\%) was calculated according to Eq. (3)

$\alpha_{3}=\frac{m_{s r 2}(g)-m_{c a t}(g)}{m_{w}(g)} \times 100 \%$

Where: $\mathrm{m}_{\text {cat }}$ is the mass of the catalyst $(\mathrm{g})$. 
Wood conversion $\left(\chi_{\mathrm{w}}\right)$ was calculated according to Eq. (4):

$\chi_{\mathrm{w}}=\frac{m_{w}(g)+m_{c a t}(g)-m_{s r 2}(g)}{m_{w}(g)} \times 100 \%$,

The liquid products of wood hydrogenolysis, after removal of the ethanol, were extracted with dichloromethane (DCM) and water according to the procedure [37]. After removal of the dichloromethane soluble products were analyzed by gel permeation chromatography (GPC).

\subsection{Analytical methods}

GC-MS analysis

An aliquot of the liquid products soluble in ethanol was analyzed by gas chromatographymass spectrometry (GC-MS) using an Agilent 7890A chromatograph fitted with an Agilent 7000A Triple Quad mass-selective detector (Agilent, USA) by recording the total ion current. The chromatographic separation of products was performed using an HP-5MS capillary column (30 $\mathrm{m} \times$ $0.25 \mathrm{~mm}$ i.d) in the temperature-programmed mode while raising the temperature from 40 to $250{ }^{\circ} \mathrm{C}$ at of $3{ }^{\circ} \mathrm{C} / \mathrm{min}$. Identification of chromatographic peaks was carried out according to the NIST MS library and the literature data on bio-oils composition. To quantify the yield of monomer compounds, the standard substances, such as phenol, guaiacol, vanillin, syring aldehyde, 4-methylphenol, (Sigma - Aldrich), ethyl palmitate (Tokyo Chem. Ind.) were used. The response factor for each standard compound was defined relative to the internal standard [38]. Phenanthrrene was used as an internal standard.

GPC analysis

The average molecular weight $(\mathrm{Mw})$, number average molecular weight $(\mathrm{Mn})$ and the polydispersity (D) of liquid products were determined by gel permeation chromatography using an Agilent 1260 Infinity II Multi-Detector GPC / SEC System with a triple detection: refractometer, viscometer and light diffusion. Separation was performed on a PLgel Mixed-E column using 250 ppm BHT stabilized tetrahydrofuran as the mobile phase. Column calibration was carried out using polydispersed polystyrene standards (Agilent, USA). The eluent feed rate was $1 \mathrm{ml} / \mathrm{min}$ and the sample volume was $100 \mu \mathrm{l}$. Before analysis, the samples were dissolved in THF $(1 \mathrm{mg} / \mathrm{ml})$ and filtered through a $0.45 \mu \mathrm{m}$ membrane PTFE filter (Millipore). Data collection and processing was performed using Agilent GPC / SEC MDS software.

\section{$\underline{\mathrm{GC} \text { analysis }}$}

The composition of the gaseous products of thermal conversion was determined with the use of gas chromatograph by Crystal 2000 M (Khromatek, Russia) with a thermal conductivity detector. Carrier gas helium (flow rate $15 \mathrm{ml} / \mathrm{min}$ ). The temperature of the detector is $170{ }^{\circ} \mathrm{C}$. For analysis of $\mathrm{CO}$ and $\mathrm{CH}_{4}$, a column with $\mathrm{NaX}$ zeolite $(3 \mathrm{~m} * 2 \mathrm{~mm})$ was used in isothermal mode at a temperature of $60{ }^{\circ} \mathrm{C}$. Analysis of $\mathrm{CO}_{2}$ and hydrocarbon gases was carried out on a column with 
Porapak Q in the mode: $1 \mathrm{~min}-60{ }^{\circ} \mathrm{C}$ and then the temperature was increased to $180{ }^{\circ} \mathrm{C}$ at a rate of $10{ }^{\circ} \mathrm{C} / \mathrm{min}$. Total yield of gaseous products $\left(\alpha_{4}\right)$ was calculated according to Eq.5

$\alpha_{4}=\frac{m_{g}(g)}{m_{w}(g)} \times 100 \%$

Where: $\mathrm{m}_{\mathrm{g}}$ is the mass of the gaseous products $(\mathrm{g})$.

\section{Chemical analysis}

The content of residual lignin in the cellulose product was determined in the modification of Komarov [39], by hydrolysis of $72 \%$ sulfuric acid hemicellulose - by hydrolysis of $2 \%$ hydrochloric acid according to [40]. The cellulose content was calculated by the difference between the mass of the solid residue and the contents of hemicelluloses and lignin. The conversion of hemicelluloses $\left(\chi_{h}\right)$, cellulose $\left(\chi_{\mathrm{c}}\right)$ and lignin $\left(\chi_{1}\right)$ was calculated by the formulas 6-8:

$$
\begin{aligned}
& \chi_{\mathrm{h}}=\frac{\mathrm{m}_{\mathrm{hw}}-\mathrm{m}_{\mathrm{hsr}}}{\mathrm{m}_{\mathrm{hw}}} \cdot 100 \% \\
& \chi_{1}=\frac{\mathrm{m}_{\mathrm{lw}}-\mathrm{m}_{\mathrm{lsr}}}{\mathrm{m}_{\mathrm{hw}}} \cdot 100 \% \\
& \chi_{\mathrm{c}}=\frac{\mathrm{m}_{\mathrm{cw}}-\mathrm{m}_{\mathrm{csr}}}{\mathrm{m}_{\mathrm{cw}}} \cdot 100 \%
\end{aligned}
$$

Where: $m_{h w}$ and $m_{h s r}$ are the mass of hemicelluloses in wood and in the solid residue after extraction with water, $g ; m_{l w}$ and $m_{l s r}$ - mass of lignin in wood and in the solid residue after extraction with water, $g ; m_{c w}$ and $m_{c s r}$ are the mass of cellulose wood and in the solid residue after extraction with water.

The elemental composition of wood and the liquid products was determined using an HCNS-O EAFLAS HTM 1112 analyzer (Thermo Quest).

\section{Results and discussion}

\subsection{Thermal depolymerization of aspen wood in supercritical ethanol medium}

The impact of temperature and pressure of the process of aspen wood thermal depolymerization in supercritical ethanol on the wood conversion and on the yield of liquid, solid and gaseous products was studied. At the process temperatures $270{ }^{\circ} \mathrm{C}$ and $350{ }^{\circ} \mathrm{C}$ the conversion of wood significantly increases with the rise of pressure from 4.0 MPa to 20.8 MPa (Fig. 2). 


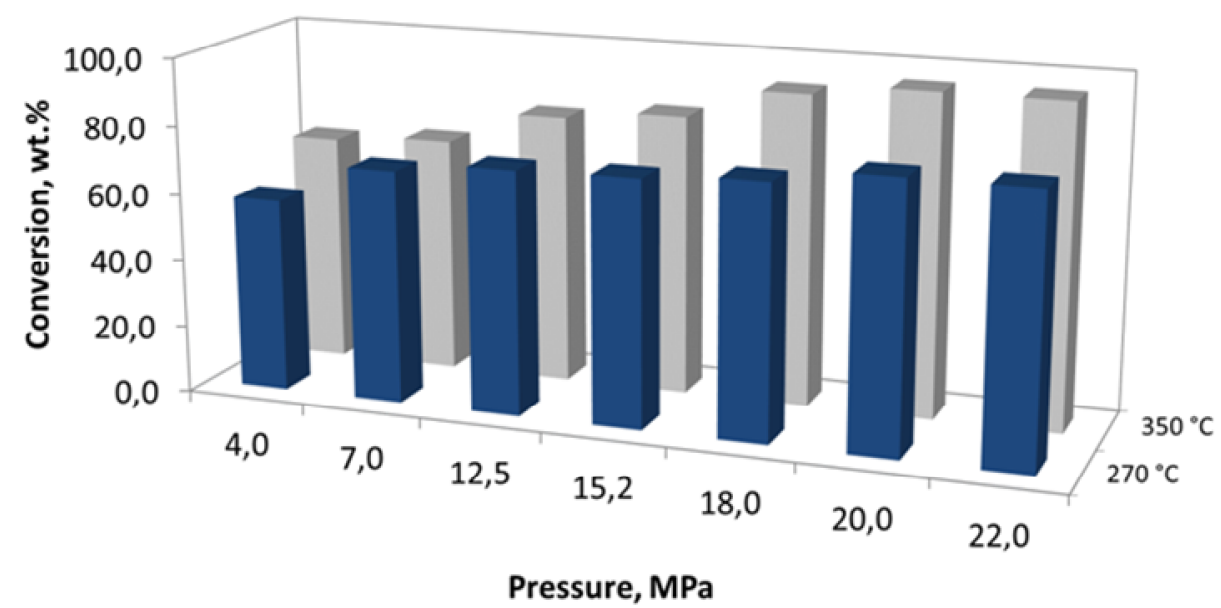

Fig. 2. Effect of pressure and temperature on the conversion of aspen wood (process time $3 \mathrm{~h}$ ).

The most high conversion of aspen wood $(95.5 \mathrm{wt} \%)$ is reached at the process temperature $350{ }^{\circ} \mathrm{C}$ and pressure 20.8 MPa. In subcritical conditions (pressure 4.0 $\mathrm{MPa}$ and process temperature $270{ }^{\circ} \mathrm{C}$ ) the yield of ethanol-soluble products reaches $55.2 \mathrm{wt} \%$. More than $60 \%$ of these liquid products belong to the light fraction with b.p. $\leq 100{ }^{\circ} \mathrm{C}$. The rise of a process pressure up to $22 \mathrm{MPa}$ increases the yield of ethanol-soluble products to $76.2 \mathrm{wt} \%$ and reduces the yield of solid rest (Fig. 3).

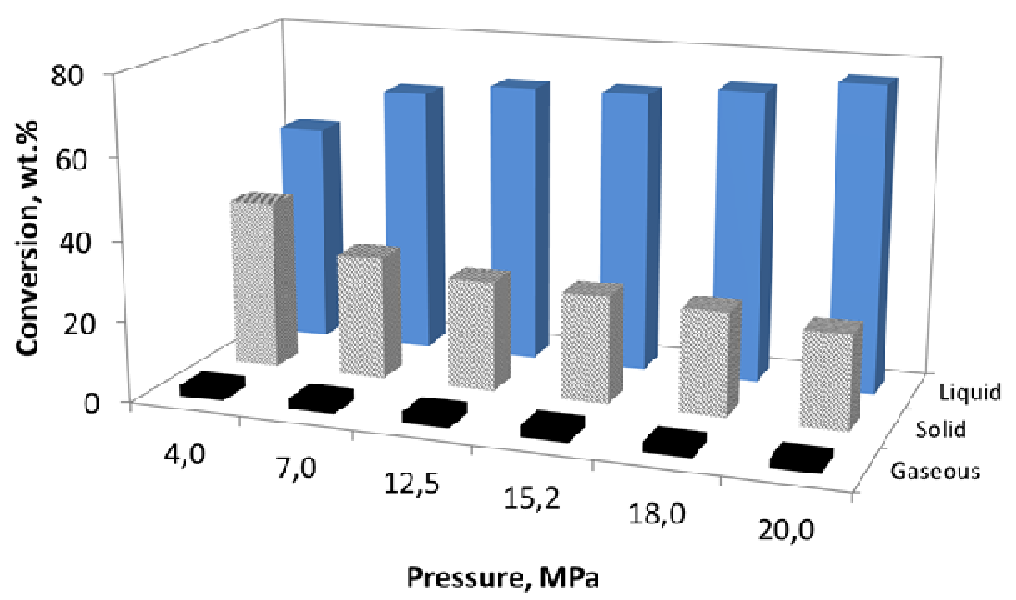

Fig. 3. Effect of pressure on the yield of products of aspen wood thermal depolymerization in ethanol at $270{ }^{\circ} \mathrm{C}$ (process time $3 \mathrm{~h}$ ).

The influence of temperature and pressure on the conversion of main wood components (cellulose, hemicelluloses, lignin) was studied (Fig. 4). Hemicelluloses undergo the most intense depolymerization and their conversion reaches to $100 \%$ already at pressure of $15.2 \mathrm{MPa}$. At the process pressure 20.0 $\mathrm{MPa}$ the conversion of lignin reaches $70 \mathrm{wt} \%$. Cellulose is the most inert component of wood. The solid residue of aspen wood depolymerization in supercritical ethanol at $270{ }^{\circ} \mathrm{C}$ and pressure $20 \mathrm{MPa}$ contains $71 \mathrm{wt} \%$ of cellulose (Fig. 4). 


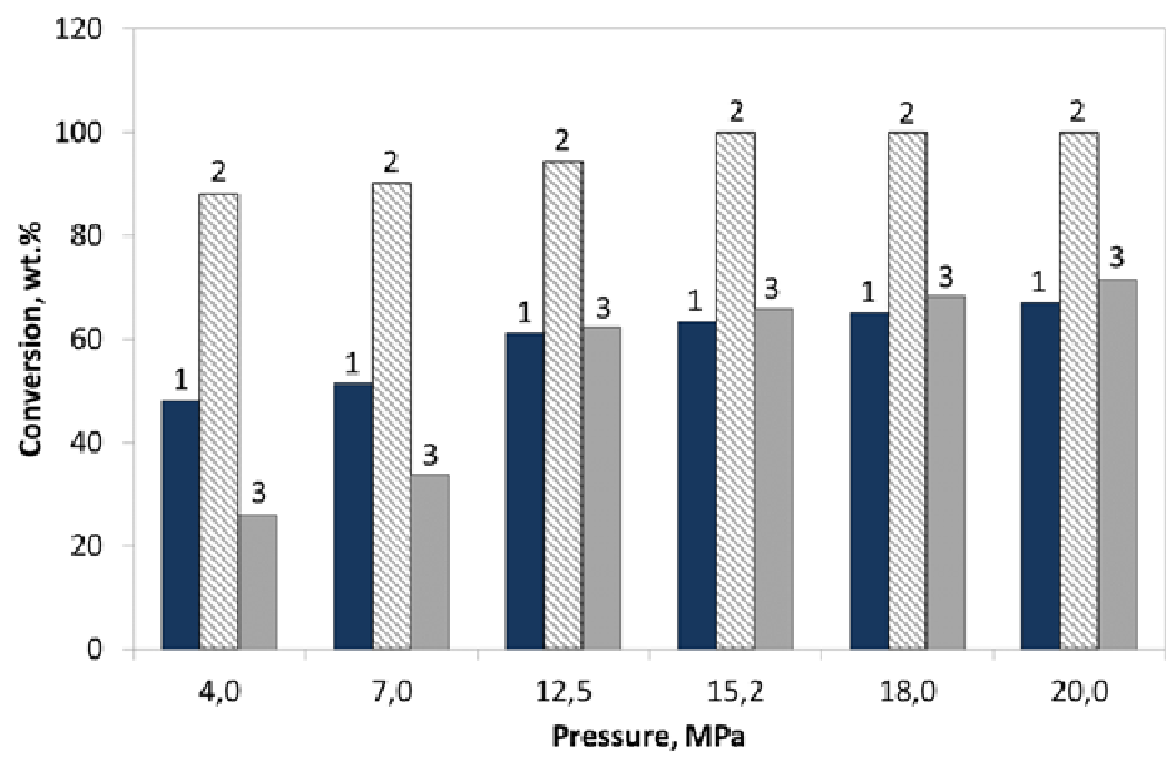

Fig. 4. Effect of pressure on the conversion of the main components of aspen wood in the process of thermal depolymerization in ethanol at $270{ }^{\circ} \mathrm{C}: 1-$ cellulose, 2 - hemicelluloses, 3 - lignin (process time $3 \mathrm{~h}$ ).

The rise of the temperature from 270 to $350{ }^{\circ} \mathrm{C}$ increases the yield of ethanol-soluble and gaseous products and reduces the yield of solid rest. At the temperature of $350{ }^{\circ} \mathrm{C}$ the rise of pressure from 4 to $20 \mathrm{MPa}$ increases by 2 time the yield of ethanol-soluble product (up to $91 \mathrm{wt} \%$ ) (Table 1).

\section{Table 1}

Effect of pressure on the yield of products of thermal depolymerization of aspen wood in ethanol $\left(350{ }^{\circ} \mathrm{C}, 3 \mathrm{~h}\right)$.

\begin{tabular}{|l|c|c|c|c|c|c|c|}
\hline \multirow{2}{*}{\multicolumn{1}{c|}{ Products }} & \multicolumn{7}{|c|}{ Solvent pressure, MPa } \\
\cline { 2 - 7 } & 4.0 & 7.0 & 12.5 & 15.2 & 18.0 & 20.0 \\
\cline { 2 - 7 } & \multicolumn{7}{|c|}{ Yield, wt.\% } \\
\hline Ethanol soluble & 46.8 & 49.8 & 64.1 & 73.5 & 86.1 & 91.0 \\
\hline Gaseous & 21.3 & 20.4 & 16.2 & 9.7 & 6.21 & 4.1 \\
\hline Solid residue & 31.9 & 29.5 & 19.7 & 16.8 & 7.7 & 4.5 \\
\hline
\end{tabular}

* subcritical pressure of the solvent.

\subsection{Catalytic hydrogenolysis of aspen wood in supercritical ethanol medium}

Taking into account the results of the study of aspen wood thermal depolymerization in ethanol medium, the following conditions for catalytic hydrogenolysis of wood in supercritical ethanol were chosen: temperature $250{ }^{\circ} \mathrm{C}$, pressure $9 \mathrm{MPa}$. At these conditions the catalytic properties of bifunctional catalysts $\mathrm{Ru} / \mathrm{C}, \mathrm{Pt} / \mathrm{ZrO}_{2}$ and $\mathrm{NiCuMo} / \mathrm{SiO}_{2}$ were compared (Fig. 5). 


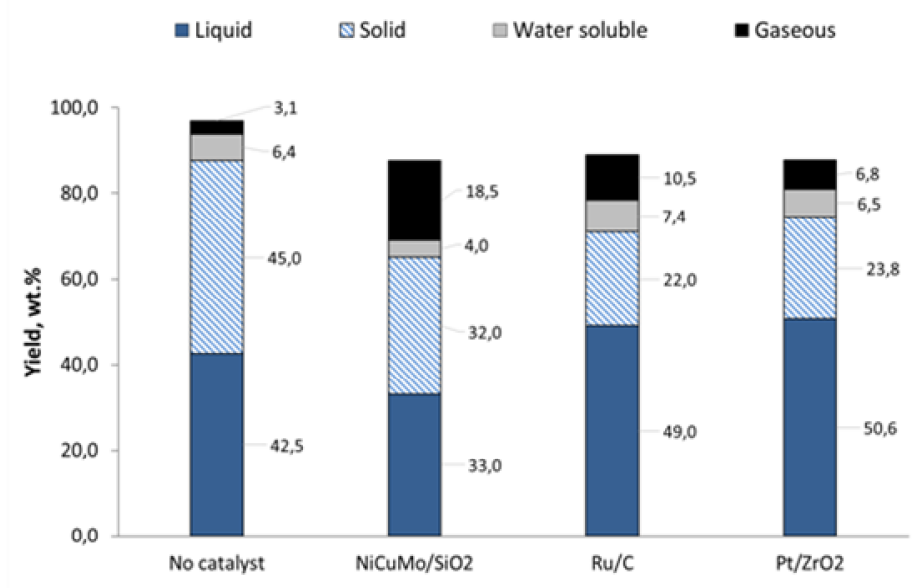

Fig. 5. Yield of products of aspen wood catalytic hydrogenolysis $\left(250{ }^{\circ} \mathrm{C}, 9 \mathrm{MPa}, 3 \mathrm{~h}\right)$.

The conversion of aspen wood in the process of non-catalytic hydrogenolysis at $250{ }^{\circ} \mathrm{C}$ is $55.0 \mathrm{wt} \%$ (Table 2), the yields of liquid and gaseous products are $42.5 \mathrm{wt} \%$ and $45 \mathrm{wt} \%$, respectively (Fig. 5). All catalysts increase the conversion of wood and the yield of gaseous products compared to non-catalytic hydrogenolysis process. Catalysts reduce the yield of solid residue but have only little effect on the yield of liquid products (Table 2, Fig. 5). The most effective is the catalyst $\mathrm{Ru} / \mathrm{C}$, which provide the high conversion of wood (78 wt \%), significant yield of liquid products $\left(49 \mathrm{wt} \%\right.$ ) and low yield of solid residue (22 wt\%). Catalyst $\mathrm{Pt} / \mathrm{ZrO}_{2}$ is somewhat inferior to ruthenium catalyst in its efficiency but superior to it in terms of low yield of gaseous products $(6.8 \mathrm{wt} \%$ instead of $10.5 \mathrm{wt} \%)$.

\section{Table 2}

Conversion of aspen wood and its structural components in catalytic hydrogenolysis in supercritical ethanol $\left(250{ }^{\circ} \mathrm{C}, 9 \mathrm{MPa}, 3 \mathrm{~h}\right)$.

\begin{tabular}{|l|c|c|c|c|}
\hline \multirow{2}{*}{ Catalyst } & \multirow{2}{*}{$\begin{array}{c}\text { Conversion of } \\
\text { wood, wt. \% }\end{array}$} & \multicolumn{3}{|l|}{ Conversion of the structural components of wood, wt. \% } \\
\cline { 3 - 5 } & 55.0 & Hemicelluloses & Lignin & Cellulose \\
\hline No catalyst & 68.0 & 95.0 & 36.7 & 43.0 \\
\hline $\mathrm{NiCuMo} / \mathrm{SiO}_{2}$ & 78.0 & 96.9 & 67.2 & 46.9 \\
\hline $\mathrm{Ru} / \mathrm{C}$ & 76.2 & 97.7 & 78.4 & 60.3 \\
\hline $\mathrm{Pt} / \mathrm{ZrO} \mathrm{ran}_{2}$ & \multicolumn{3}{|l}{} \\
\hline
\end{tabular}

The influence of hydrogenolysis conditions on the yield and composition of gaseous products is illustrated by Fig. 6. In gaseous products of non-catalytic hydrogenolysis of aspen wood dominates $\mathrm{CO}_{2}$. In the composition of gaseous products of wood hydrogenolysis in the presence of catalysts $\mathrm{NiCuMo} / \mathrm{SiO}_{2}$ and $\mathrm{Ru} / \mathrm{C}$ the main component is $\mathrm{CO}$. Carbon oxides and methane are formed as a result of the reactions of decarbonylation, decarboxylation and cracking of the functional group of wood biomass. 


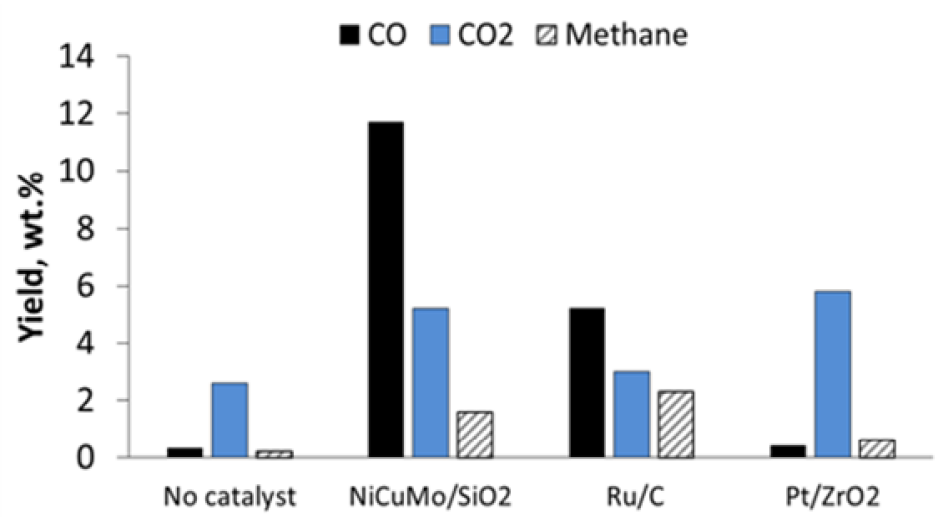

Fig. 6. Yield of gaseous products of aspen wood catalytic hydrogenolysis $\left(250{ }^{\circ} \mathrm{C}, 9 \mathrm{MPa}, 3 \mathrm{~h}\right)$.

According to chemical analysis date, the solid rest of non-catalytic hydrogenolysis of wood contains $68.6 \mathrm{wt} \%$ of cellulose and $28.7 \mathrm{wt} \%$ of lignin (Table 3 ). Catalysts increase the content of cellulose in solid rest to $76.8 \mathrm{wt} \%\left(\mathrm{NiCuMo} / \mathrm{SiO}_{2}\right)$ to $77.3 \mathrm{wt} \%(\mathrm{Ru} / \mathrm{C})$ and to $82.2 \mathrm{wt} \%\left(\mathrm{Pt} / \mathrm{ZrO}_{2}\right)$. At the same time, the lignin content in the solid residue is decreased to a minimum value $15.9 \mathrm{wt} \%$ in the presence of catalyst $\mathrm{Pt} / \mathrm{ZrO}_{2}$ (Table 3). The content of hemicelluloses in solid residue does not exceed $2.7 \mathrm{wt} \%$.

\section{Table 3}

Composition of solid products formed in the process of aspen wood catalytic hydrogenolysis $\left(250{ }^{\circ} \mathrm{C}, 9 \mathrm{MPa}, 3 \mathrm{~h}\right)$.

\begin{tabular}{|l|c|c|c|}
\hline \multirow{2}{*}{ Catalyst } & \multicolumn{3}{|c|}{ The composition of solid products, wt. \% } \\
\cline { 2 - 4 } & Cellulose & Lignin & Hemicelluloses \\
\hline No catalyst & 68.6 & 28.7 & 2.7 \\
\hline $\mathrm{NiCuMo} / \mathrm{SiO}_{2}$ & 76.8 & 20.9 & 2.3 \\
\hline $\mathrm{Ru} / \mathrm{C}$ & 77.3 & 20.1 & 2.6 \\
\hline $\mathrm{Pt} / \mathrm{ZrO}$ & 82.2 & 15.9 & 1.9 \\
\hline
\end{tabular}

Results of elemental analysis of liquid products of wood hydrogenolysis are presented in Table 4. Catalysts promote the hydrodeoxygenation reactions, reducing the content of oxygen in liquid products from $31.6 \mathrm{wt} \%$ (non-catalytic hydrogenolysis) to $27.9 \mathrm{wt} \%(\mathrm{Ru} / \mathrm{C})$.

\section{Table 4}

Elemental composition of aspen wood and liquid products obtained by hydrogenolysis of aspen wood $\left(250{ }^{\circ} \mathrm{C}, 9 \mathrm{MPa}\right.$, time $\left.3 \mathrm{~h}\right)$.

\begin{tabular}{|c|c|c|c|}
\hline Sample & $\mathrm{C}, \mathrm{wt} \%$ & $\mathrm{H}, \mathrm{wt} \%$ & $\mathrm{O}, \mathrm{wt} \%$ \\
\hline Aspen Wood & 49.9 & 6.1 & 44.0 \\
\hline \multicolumn{4}{|c|}{ Liquid products } \\
\hline No catalyst & 61.9 & 6.5 & 31.6 \\
\hline Catalyst $\mathrm{NiCuMo} / \mathrm{SiO}_{2}$ & 62.5 & 6.9 & 30.7 \\
\hline Catalyst $\mathrm{Ru} / \mathrm{C}$ & 63.9 & 8.2 & 27.9 \\
\hline Catalyst $\mathrm{Pt} / \mathrm{ZrO}_{2}$ & 63.3 & 7.1 & 29.6 \\
\hline Cellulose (calculation) & 44.4 & 6.2 & 49.4 \\
\hline
\end{tabular}


The analysis of liquid products of aspen wood hydrogenolysis was carried out by GC-MS method. Individual compounds identified in liquid products are given in Table 5.

\section{Table 5}

Effect of catalysts on the composition and relative yield of individual compounds formed in the process of aspen wood catalytic hydrogenolysis $\left(250^{\circ} \mathrm{C}, 9 \mathrm{MPa}, 3 \mathrm{~h}\right)$.

\begin{tabular}{|c|c|l|c|c|c|c|}
\hline \multirow{2}{*}{$\begin{array}{c}\text { № } \\
\Pi / \Pi\end{array}$} & \multirow{2}{*}{ RT } & & \multicolumn{4}{|c|}{ Yield, wt\%* } \\
\cline { 3 - 7 } & & $\mathrm{No} /$ cat. & $\mathrm{NiCuMo} / \mathrm{SiO}_{2}$ & $\mathrm{Ru} / \mathrm{C}$ & $\mathrm{Pt} / \mathrm{ZrO}_{2}$ \\
\hline 1 & 14.19 & Phenol & 1.0 & 0.5 & 0.7 & 1.5 \\
\hline 2 & 18.13 & Guaiacol & 0.4 & 0.00 & 0.0 & 0.0 \\
\hline 3 & 21.74 & Methyl guaiacol & 0.00 & 0.2 & 0.1 & 0.1 \\
\hline 4 & 24.38 & Ethyl guaiacol & $\mathbf{0 . 5}$ & $\mathbf{2 . 5}$ & $\mathbf{1 . 0}$ & $\mathbf{0 . 8}$ \\
\hline 5 & 26.45 & Syringol & 2.3 & 0.5 & 0.8 & 0.7 \\
\hline 6 & 26.82 & Propyl guaiacol & $\mathbf{0 . 3}$ & $\mathbf{2 . 3}$ & $\mathbf{1 3 . 3}$ & $\mathbf{1 3 . 9}$ \\
\hline 7 & 27.92 & Propenyl guaiacol & 0.8 & 0.0 & 0.2 & 0.3 \\
\hline 8 & 28.97 & Methyl siringol & 0.00 & 0.5 & 0.00 & 0.0 \\
\hline 9 & 30.93 & Ethyl syringol & $\mathbf{0 . 7}$ & $\mathbf{4 . 1}$ & $\mathbf{2 . 1}$ & $\mathbf{1 . 8}$ \\
\hline 10 & 32.89 & Propyl syringol & $\mathbf{0 . 7}$ & $\mathbf{7 . 0}$ & $\mathbf{2 1 . 3}$ & $\mathbf{2 0 . 5}$ \\
\hline 11 & 33.86 & Syring aldehyde & $\mathbf{1 . 0}$ & $\mathbf{5 . 4}$ & $\mathbf{2 . 7}$ & $\mathbf{2 . 7}$ \\
\hline 12 & 34.98 & Propenyl syringol & $\mathbf{9 . 5}$ & 0.00 & 0.4 & 0.6 \\
\hline \multicolumn{2}{|c|}{ Total yield of compounds } & $\mathbf{2 3 . 1}$ & $\mathbf{4 2 . 6}$ & $\mathbf{4 2 . 9}$ \\
\hline
\end{tabular}

*-on mass of lignin, $\%$

It was found that alkyl derivatives of metoxyphenols predominate in the liquid products. In non-catalytic hydrogenolysis their total yield does not exceed $9.5 \mathrm{wt} \%$. Bifunctional catalysts significantly increase the total yield of alkyl derivatives of methoxyphenols, which reaches to 42.6$42.9 \%$ from mass of lignin in the wood in the presence of catalysts $\mathrm{Ru} / \mathrm{C}$ and $\mathrm{Pt} / \mathrm{ZrO}_{2}$. The main monomeric compounds in liquid products are propyl syringol and propyl quaiacol. The yield of propyl syringol reaches to $20.5 \%$ and $21.3 \%$ on mass of lignin for catalysts $\mathrm{Pt} / \mathrm{ZrO}_{2}$ and $\mathrm{Ru} / \mathrm{C}$ respectively. In the presence of these catalysts the yield of propyl quaiacol reaches to $13.3-13.9 \%$ on mass of lignin.

The high yield of syringol and quaiacol derivatives indicates that bifunctional catalysts accelerate the cleavage of $\beta-\mathrm{O}-4$ bonds in the native lignin and promote the reactions of $\mathrm{C}-\mathrm{C}$ bonds breaking and $\mathrm{C}=\mathrm{C}$ bonds hydrogenation $[19,37,41]$. At temperature $250{ }^{\circ} \mathrm{C}$ supercritical ethanol extracts from wood biomass and depolymerizes to oligomeric and monomeric products less than $37 \%$ of lignin (Table 2). The conversion of native lignin increases more than 2 times in the presence of catalysts (Table 2). So, the used biofunctional catalysts not only increase the conversion of native lignin of aspen wood but raise the yield of monomeric compounds in liquid products form $9.5 \mathrm{wt} \%$ to $42.9 \mathrm{wt} \%$. 


\subsection{Thermal depolymerization of aspen ethanol lignin in supercritical ethanol medium}

The possible mechanism of catalytic hydrogenolysis of aspen wood in supercritical ethanol includes the isolation from wood the soluble ethanol lignin, which is subjected to reactions of thermal and catalytic depolymerization to liquid products.

The sample of ethanol lignin was isolated by treatment of aspen wood with supercritical ethanol at $190^{\circ} \mathrm{C}$ during 3 hours as in [32]. Elemental composition of ethanol lignin is presented in Table 6. Aspen ethanol lignin is comparable in composition to aceton lignin, isolated from aspen wood [26].

\section{Table 6}

Elemental composition of aspen ethanol lignin.

\begin{tabular}{|c|c|c|c|c|c|}
\hline \multicolumn{3}{|c|}{ The content of elements, wt.\% } & \multicolumn{2}{|c|}{ Atomic ratio } & \multirow{2}{*}{$\begin{array}{c}\text { Ash content, } \\
\mathrm{wt}^{2} \%\end{array}$} \\
\hline $\mathrm{C}$ & $\mathrm{H}$ & $\mathrm{O}$ & $\mathrm{H} / \mathrm{C}$ & $\mathrm{O} / \mathrm{C}$ & \\
\hline 64.6 & 6.8 & 26.7 & 1.3 & 0.3 & 0.5 \\
\hline
\end{tabular}

FTIR spectrum of aspen ethanol lignin contains absorption bands characteristic of phenylpropane structural units of the quaiacyl and syringyl type. According to thermogravimetric analysis, the thermal decomposition of ethanol lignin proceeds in two stages, which correspond peaks of mass loss at $300^{\circ} \mathrm{C}$ and $390{ }^{\circ} \mathrm{C}$.

The influence of temperature of ethanol lignin thermal depolymerization in supercritical ethanol medium on the yield of liquid, solid and gaseous products was studied (Fig. 7). The most high yield of benzene-soluble liquid products $(42 \mathrm{wt} \%)$ is reached at temperature $300{ }^{\circ} \mathrm{C}$.

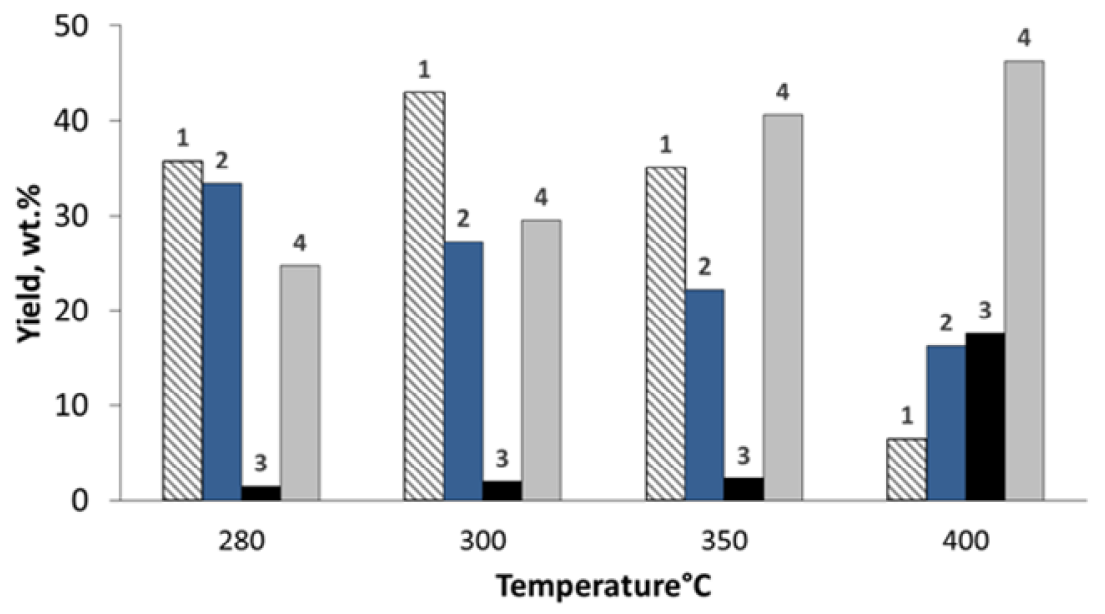

Fig. 7. Influence of the temperature of ethanol lignin depolymerization in supercritical ethanol on the yield of benzene-soluble (1), ethanol-soluble (2), gaseous (3) and solid (4) products (9,0 MPa, $3 \mathrm{~h})$. 
More than 80 individual compounds were identified by GC-MS methods in benzene-soluble products of ethanol lignin thermal depolymerization in supercritical ethanol. They contain derivatives of phenol and benzene and also ethyl esters. The presence of esters can be explained by reactions of ethanol with liquid products of lignin depolymerization [20, 21].

Group composition of benzene-soluble liquid products of ethanol lignin thermal depolymerization is given in Table 7. The rise of temperature of ethanol lignin thermal depolymerization from 280 to $300{ }^{\circ} \mathrm{C}$ increases significantly the relative content of methoxyphenols and methoxybenzenes in benzene-soluble products. The further increase in temperature does not lead to a noticeable changes in composition of these liquid products.

\section{Table 7}

Effect of the temperature of ethanol-lignin depolymerization in supercritical ethanol on the group composition of benzene-soluble products (GC-MS data)

\begin{tabular}{|l|c|c|c|}
\hline \multirow{2}{*}{ Compounds } & \multicolumn{3}{|c|}{ Content, \%* } \\
\cline { 2 - 4 } & $280{ }^{\circ} \mathrm{C}$ & $300{ }^{\circ} \mathrm{C}$ & $350^{\circ} \mathrm{C}$ \\
\hline Pnenols, & 37.4 & 55.9 & 56.9 \\
i.e. methoxyphenols & 27.9 & 44.7 & 45.9 \\
\hline Esters & 43.8 & 18.5 & 18.1 \\
\hline Benzene derivatives, & 7.5 & 17.8 & 18.4 \\
i.e. methoxybenzenes & 7.5 & 17.4 & 17.9 \\
\hline
\end{tabular}

$* \%$ on the sum of peak areas

\subsection{Catalytic hydrogenolysis of aspen ethanol lignin in supercritical ethanol medium}

The influence of bifunctional catalysts $\mathrm{Ru} / \mathrm{C}, \mathrm{Pt} / \mathrm{ZrO}{ }_{2}, \mathrm{NiCuMo} / \mathrm{SiO}_{2}$ on the yield of products of aspen ethanol lignin hydrogenolysis in supercritical ethanol medium at $250{ }^{\circ} \mathrm{C}$ was studied (Fig. 8)

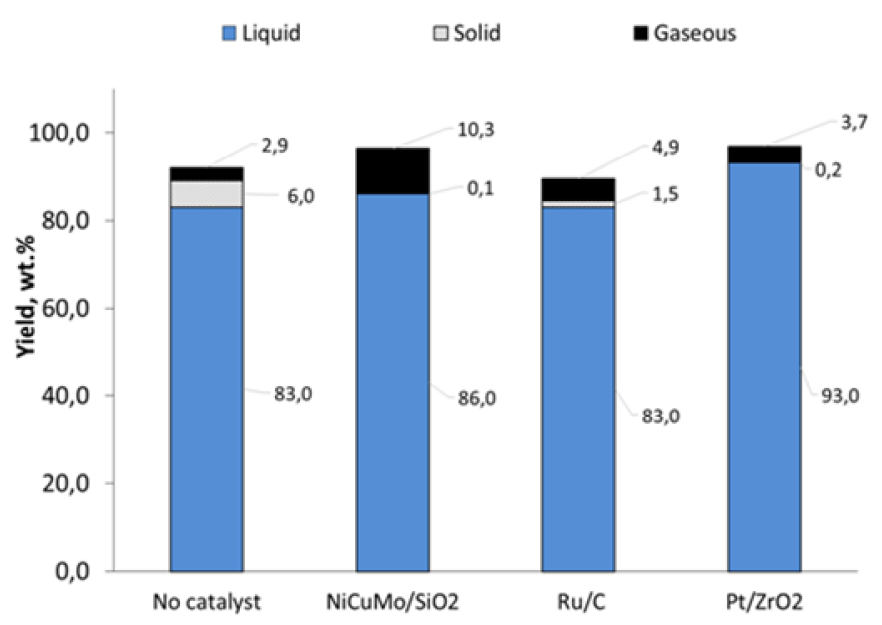

Fig. 8. Influence of catalyst nature on the yield of the products of aspen ethanol-lignin hydrogenolysis $\left(250^{\circ} \mathrm{C}, 9 \mathrm{MPa}, 3 \mathrm{~h}\right)$. 
The catalyst $\mathrm{Pt} / \mathrm{ZrO}_{2}$ increases the yield of liquid products up to $93 \mathrm{wt} \%$, while the catalysts $\mathrm{Ru} / \mathrm{C}$ and $\mathrm{NiCuMo} / \mathrm{SiO}_{2}$ have little effect on liquid products yield. All catalysts reduce the yield of solid rest, which is formed by repolymerization of lignin-based reactive intermediates [16, 42]. In the presence of hydrogen, the metal active centers of bifunctional catalyst prevent condensation reactions of intermediates resulting in lower yield of solid rest. In the presence of catalyst $\mathrm{NiCuMo} / \mathrm{SiO}_{2}$ the significant increase in the yield of gaseous products was observed (Fig. 9).

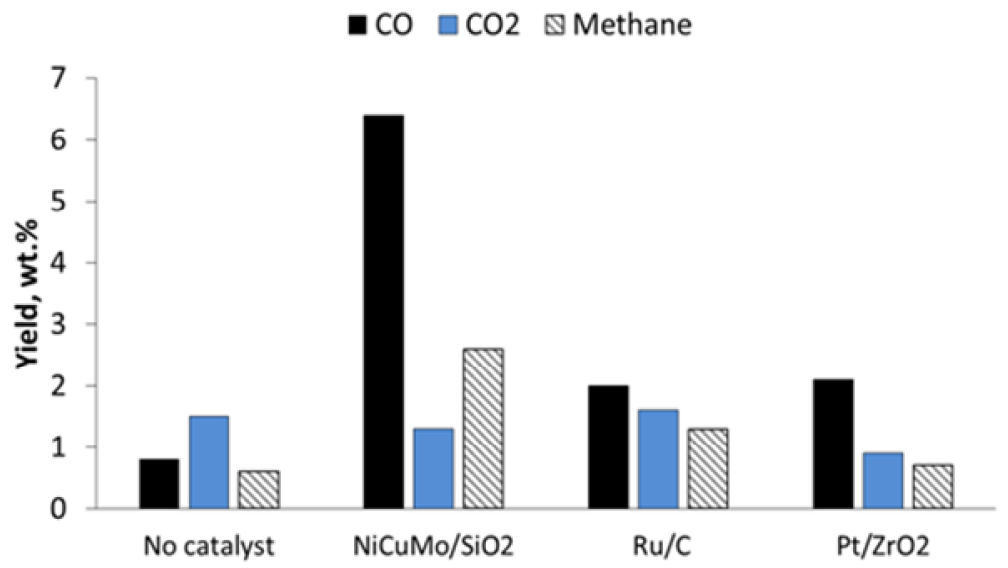

Fig. 9. Yield of gaseous products of aspen ethanol lignin catalytic hydrogenolysis $\left(250{ }^{\circ} \mathrm{C}, 9 \mathrm{MPa}\right.$, $3 \mathrm{~h})$.

This catalyst promotes the formation of carbon monoxide and methane while carbon dioxide prevails in gaseous products of non-catalytic hydrogenolysis process. The increased yield of gaseous products in the presence of bifunctional catalyst can be explained by following reasons. Acid centers of the catalyst intensify the reactions of ester bonds hydrolysis in lignin and subsequent decarbonylation of the resulting acid groups with the release of $\mathrm{CO}_{2}$. Metal centers of catalyst promote the reaction of decarbonylation of Hibbert ketones formed by acid-catalyzed depolymerization of lignin [8], and hydrocracking of methoxyphenols and phenols [43, 44] with CO and methane release.

The individual compounds formed in the processes of abies ethanol lignin catalytic hydrogenolysis were identified by GC-MS methods (Table 8). They are mainly represented by alkyl derivatives of methoxyphenols like liquid products of aspen wood hydrogenolysis.

In the process of non-catalytic hydrogenolysis of ethanol lignin the yield of phenol derivatives is $5.5 \mathrm{wt} \%$, including $4.5 \mathrm{wt} \%$ of alkyl derivatives of methoxyphenols. The bufunctional catalysts increase the yield of alkyl derivatives of methoxyphenols, but to a lesser extent than was observed in the case of catalytic hydrogenation of aspen wood. 
Table 8

Effect of catalysts on the yield of individual phenolic compounds formed in the process of aspen ethanol lignin hydrogenolysis $\left(250{ }^{\circ} \mathrm{C}, 9 \mathrm{MPa}, 3 \mathrm{~h}\right)$.

\begin{tabular}{|c|l|c|c|c|c|}
\hline \multirow{2}{*}{ RT Monomers } & \multicolumn{4}{|c|}{ Yield, $\mathrm{wt}^{*} *$} \\
\cline { 3 - 6 } & & $\mathrm{No} / \mathrm{cat}$. & $\mathrm{NiCuMo} / \mathrm{SiO}_{2}$ & $\mathrm{Ru} / \mathrm{C}$ & $\mathrm{Pt} / \mathrm{ZrO}_{2}$ \\
\hline 14.19 & Phenol & 0.19 & 0.32 & 0.28 & 0.30 \\
\hline 18.13 & Guaiacol & 0.18 & 0.23 & 0.24 & 0.11 \\
\hline 21.74 & Methyl guaiacol & 0.36 & 0.00 & 0.08 & 0.23 \\
\hline $\mathbf{2 4 . 3 8}$ & Ethyl guaiacol & $\mathbf{0 . 2 8}$ & $\mathbf{0 . 4 1}$ & $\mathbf{0 . 5 0}$ & $\mathbf{0 . 2 9}$ \\
\hline $\mathbf{2 6 . 4 5}$ & Syringol & $\mathbf{0 . 3 9}$ & $\mathbf{0 . 5 4}$ & $\mathbf{0 . 4 0}$ & $\mathbf{0 . 2 2}$ \\
\hline $\mathbf{2 6 . 8 2}$ & Propyl syringol & $\mathbf{0 . 6 9}$ & $\mathbf{1 . 1 1}$ & $\mathbf{1 . 5 0}$ & $\mathbf{2 . 0 3}$ \\
\hline $\mathbf{2 8 . 9 7}$ & Methyl syringol & $\mathbf{0 . 8 5}$ & $\mathbf{0 . 9 9}$ & $\mathbf{0 . 3 0}$ & $\mathbf{0 . 2 6}$ \\
\hline 29.03 & Propenyl guaiacol & 0.02 & 0.05 & 0.05 & 0.03 \\
\hline 30.05 & Acetoguaiacone (Acetovanillone) & 0.04 & 0.04 & 0.04 & 0.02 \\
\hline $\mathbf{3 0 . 9 3}$ & Ethyl syringol & $\mathbf{0 . 6 0}$ & $\mathbf{0 . 7 1}$ & $\mathbf{0 . 6 0}$ & $\mathbf{0 . 3 2}$ \\
\hline 31.22 & Homovanillyl alcohol & & 0.64 & 0.60 & 0.73 \\
\hline 32.38 & Ethyl vanillate & 0.03 & 0.01 & 0.01 & 0.04 \\
\hline $\mathbf{3 2 . 8 8}$ & Propyl syringol & $\mathbf{1 . 7 5}$ & $\mathbf{2 . 3 2}$ & $\mathbf{2 . 1 0}$ & $\mathbf{4 . 1 6}$ \\
\hline 33.70 & Ethylhomovanillate & 0.04 & 0.04 & 0.04 & \\
\hline 34.25 & Propenyl syringol & 0.08 & 0.14 & 0.19 & 0.09 \\
\hline 35.77 & Acetosyringone & 0.12 & 0.04 & 0.04 & 0.01 \\
\hline 35.99 & Ethyl- $\beta$-(4-hydroxy-phenyl)-propionate & 0.01 & 0.01 & 0.01 & 0.01 \\
\hline & Total yield & $\mathbf{5 . 6 3}$ & $\mathbf{7 . 6}$ & $\mathbf{6 . 9 8}$ & $\mathbf{8 . 8 5}$ \\
\hline
\end{tabular}

*on mass of lignin, \%

The sharp decrease in the yield of monomeric products from ethanol lignin compared to wood is probably due to reduced content of ether $\beta-\mathrm{O}-4$ bonds in the structure of ethanol lignin in comparison with native lignin of aspen wood. Obviously, in the process of ethanol lignin isolation from aspen wood the reactions of condensation take place [18]. They reduce the content of reactive ether bonds and increase the content of low-reactive $\mathrm{C}-\mathrm{C}$ bonds in ethanol lignin compared to native lignin. As a result, the content of monomeric derivatives of phenol in liquid products obtained by ethanol lignin hydrogenolysis is less than in the case of wood hydrogenolysis (Table 9).

Table 9

Effect of catalysts on the yield of monomeric phenol derivatives in the process of aspen ethanol lignin hydrogenolysis $\left(250{ }^{\circ} \mathrm{C}, 9 \mathrm{MPa}, 3 \mathrm{~h}\right)$.

\begin{tabular}{|l|c|c|c|c|}
\hline \multirow{2}{*}{ Monomers } & \multicolumn{4}{|c|}{ Yield, $\mathrm{wt}^{*} \mathbf{*}^{*}$} \\
\cline { 2 - 5 } & $\mathrm{No} /$ cat. & $\mathrm{NiCuMo} / \mathrm{SiO}_{2}$ & $\mathrm{Ru} / \mathrm{C}$ & $\mathrm{Pt} / \mathrm{ZrO}_{2}$ \\
\hline Ethyl guaiacol & 0.28 & 0.29 & 0.50 & 0.41 \\
\hline Propyl guaiacol & 0.69 & 2.03 & 1.50 & 1.11 \\
\hline Ethyl syringol & 0.60 & 0.32 & 0.60 & 0.71 \\
\hline Propyl syringol & 1.75 & 4.16 & 2.10 & 2.32 \\
\hline Syringol & 0.39 & 0.22 & 0.40 & 0.54 \\
\hline Methyl syringol & 0.85 & 0.26 & 0.30 & 0.99 \\
\hline Total yield & $\mathbf{4 . 5 6}$ & $\mathbf{7 . 2 8}$ & $\mathbf{5 . 5}$ & $\mathbf{6 . 0 8}$ \\
\hline
\end{tabular}

*on mass of lignin, $\%$ 
The influence of catalyst nature on the molecular mass distribution (MMD) of liquid products of aspen wood and ethanol lignin hydrogenolysis was studied by GPC method. All bifunctional catalysts shift the MMD of liquid products to the region of lower molecular mass (Fig. 10, Table 10).

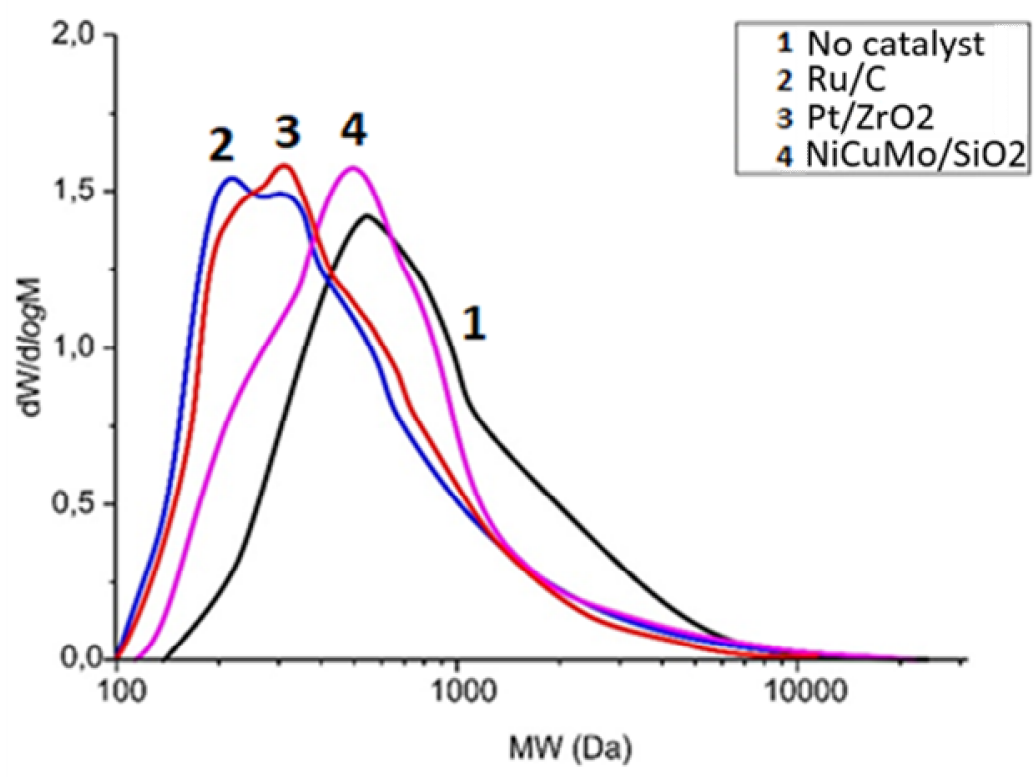

Fig. 10. Molecular mass distribution curves of liquid products of aspen wood hydrogenolysis $\left(250{ }^{\circ} \mathrm{C}, 9 \mathrm{MPa}, 3 \mathrm{~h}\right.$.

Table 10

Molecular mass characteristics of liquid products of aspen wood hydrogenolysis $\left(250^{\circ} \mathrm{C}, 9 \mathrm{MPa}, 3 \mathrm{~h}\right)$.

\begin{tabular}{|l|c|c|c|}
\hline \multicolumn{1}{|c|}{ Catalyst } & $\mathrm{Mn}(\mathrm{Da})$ & $\mathrm{Mw}(\mathrm{Da})$ & $\mathrm{D}$ \\
\hline $\mathrm{No}$ catalyst & 643 & 1155 & 1.80 \\
\hline $\mathrm{NiCuMo} / \mathrm{SiO}_{2}$ & 572 & 906 & 1.58 \\
\hline $\mathrm{Ru} / \mathrm{C}$ & 398 & 731 & 1.84 \\
\hline $\mathrm{Pt} / \mathrm{ZrO}_{2}$ & 376 & 727 & 1.93 \\
\hline
\end{tabular}

The most significant shift is observed for catalyst $\mathrm{Ru} / \mathrm{C}$ and the least - in the case of catalyst $\mathrm{NiCuMo} / \mathrm{SiO}_{2}$. All catalysts change the profile of MMD curve. When the catalyst $\mathrm{NiCuMo} / \mathrm{SiO}_{2}$ is used the region higher $1000 \mathrm{Da}$ practically disappears and the intensity of peak with MM 400-600 Da increases. Catalysts $\mathrm{Pt} / \mathrm{ZrO}_{2}$ and $\mathrm{Ru} / \mathrm{C}$ increase the content of monomeric compounds in liquid products and reduce the content of oligomers with MM 400-600 Da.

Liquid products of ethanol lignin hydrogenolysis have a more broad range of MMD than that obtained by hydrogenolysis of aspen wood (Fig. 11, Table 11). 


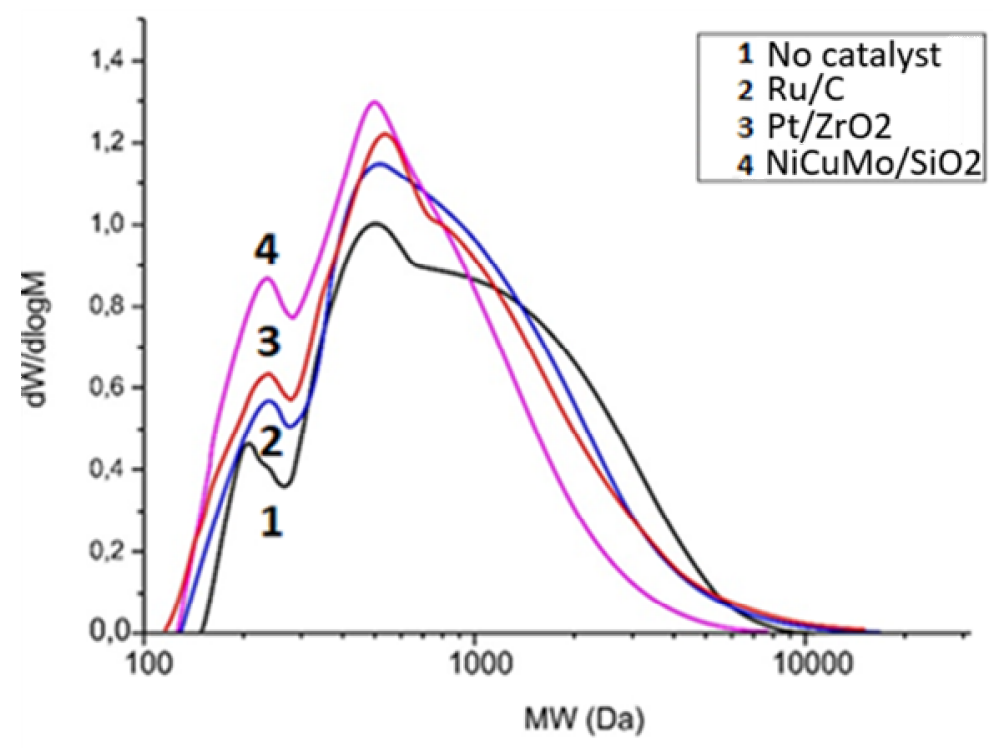

Fig. 11. Molecular mass distribution curves of liquid products of aspen ethanol lignin hydrogenolysis $\left(250{ }^{\circ} \mathrm{C}, 9 \mathrm{MPa}, 3 \mathrm{~h}\right)$.

\section{Table 11}

Molecular mass characteristics of the liquid products of aspen ethanol lignin hydrogenolysis $\left(250{ }^{\circ} \mathrm{C}, 9 \mathrm{MPa}, 3 \mathrm{~h}\right)$.

\begin{tabular}{|l|c|c|c|}
\hline \multicolumn{1}{|c|}{ Catalyst } & $\mathrm{Mn}(\mathrm{Da})$ & $\mathrm{Mw}(\mathrm{Da})$ & $\mathrm{D}$ \\
\hline $\mathrm{No}$ catalyst & 647 & 1301 & 2.01 \\
\hline $\mathrm{NiCuMo} / \mathrm{SiO}_{2}$ & 468 & 771 & 1.64 \\
\hline $\mathrm{Ru} / \mathrm{C}$ & 636 & 1147 & 1.80 \\
\hline $\mathrm{Pt} / \mathrm{ZrO}_{2}$ & 567 & 1112 & 1.96 \\
\hline
\end{tabular}

They contain mainly the fragments of lignin depolymerization with MM from 1000 to 10000Da and oligomers (mainly dimers) with MM 400-600 Da. The low content of monomeric compounds in liquid products of ethanol lignin hydrogenolysis can be explained by the increased contribution of repolymerization reactions with the participation of lignin-based intermediates. The average molecular weight $\left(\mathrm{M}_{\mathrm{w}}\right)$ of aspen ethanol lignin is $2230 \mathrm{Da}$. For liquid products of noncatalytic hydrogenolysis of ethanol lignin $\mathrm{M}_{\mathrm{w}}$ decreases to $1301 \mathrm{Da}$ (Table 11). The catalysts shift the MMD curve of liquid products of ethanol lignin hydrogenolysis to the region of lower molecular mass and change its profile. The intensity of peak with MM 200 Da increases in the presence of catalysts, which indicates an increase in the content of monomeric compounds in liquid products of ethanol lignin catalytic hydrogenolysis.

The results of the study show that the native lignin of aspen wood is easier depolymerized to monomeric compounds in the process of catalytic hydrogenolysis compared to ethanol lignin isolated from aspen wood. 


\section{Conclusion}

Catalytic properties of bifuctional catalysts $\mathrm{Ru} / \mathrm{C}, \mathrm{Pt} / \mathrm{ZrO}_{2}, \mathrm{NiCuMo} / \mathrm{SiO}_{2}$, containing nanosized metal particles on acidic supports were compared in the processes of aspen wood and ethanol lignin hydrogenolysis in supercritical ethanol at $250{ }^{\circ} \mathrm{C}$ and $9 \mathrm{MPa}$.

In non-catalytic hydrogenolysis of aspen wood at $250{ }^{\circ} \mathrm{C}$ the conversion of wood is $55 \mathrm{wt} \%$, yield of liquid products $42 \mathrm{wt} \%$ and yield of solid rest $45 \mathrm{wt} \%$. All studied catalysts increase the conversion of wood and yield of gaseous products and reduce the yield of solid residue. They weakly affect on the yield of liquid products, but increase significantly the content of monomeric lignin-based compounds. The most effective catalysts $\mathrm{Ru} / \mathrm{C}$ and $\mathrm{Pt} / \mathrm{ZrO}_{2}$ provide high conversion of wood (78.0 wt $\%$ and $76.2 \mathrm{wt} \%)$, considerable yield of liquid products (49.0 wt $\%$ and $50.6 \mathrm{wt} \%)$ and low yield of solid residue $(22.0 \mathrm{wt} \%$ and $23.8 \mathrm{wt} \%)$. The catalysts also promote the hydrodeoxygenation reactions, reducing the content of oxygen in liquid products compared to noncatalytic hydrogenolysis. According to GPC data, the catalysts shift the molecular mass distribution of liquid products to the region of lower molecular mass.

In contrast to acid catalysts based on high silica zeolites, which promote at $270{ }^{\circ} \mathrm{C}$ the conversion of polysaccharides in supercritical ethanol medium without hydrogen [12], bifunctional catalysts $\mathrm{Ru} / \mathrm{C}, \mathrm{Pt} / \mathrm{ZrO}_{2}, \mathrm{NiCuMo} / \mathrm{SiO}_{2}$ significantly increase the yield of alkyl derivatives of methoxyphenols (mainly propyl siringol and propyl quaiacol) in the presence of $\mathrm{H}_{2}$.

Solid products of aspen wood catalytic hydrogenolysis contain up to $82.2 \mathrm{wt} \%$ of cellulose. Therefore, it is possible to fractionate the aspen wood biomass on cellulose and liquid product enriched with propyl syringol and propyl quaiacol using wood hydrogenolysis in supercritical ethanol at $250{ }^{\circ} \mathrm{C}$ in the presence of bifunctional catalysts $\mathrm{Ru} / \mathrm{C}$ and $\mathrm{Pt} / \mathrm{ZrO}_{2}$.

In the process of aspen wood hydrogenolysis the bifunctional catalysts increase the yield of alkyl derivatives of methoxyphenols to a higher extent that in the case of catalytic hydrogenation of ethanol lignin. Obviously, in the process of ethanol lignin isolation from wood the condensation reactions take place, which reduce the content of reactive ether bonds and increase the content of less reactive $\mathrm{C}-\mathrm{C}$ bonds compared to native lignin. Monomeric products of catalytic hydrogenolysis of native lignin of aspen wood have prospects to use for the production of fuel additives and components of motor fuels.

\section{Funding}

The reported study was supported by Russian Science Foundation, Grant No. 16-13-10326.

\section{Acknowledgements}

The equipment of Krasnoyarsk Regional Research Equipment Centre of SB RAS was used in present work. 
The authors acknowledge Yu.N. Malyar and A.S. Kazachenko for help in obtaining experimental data.

\section{Список литературы}

[1] C. Li, X. Zhao, A. Wang, G.W. Huber, T. Zhang, Catalytic Transformation of Lignin for the Production of Chemicals and Fuels, Chemical Reviews 115 (2015) 11559-11624.

[2] F.G. Calvo-Flores, J.A. Dobado, Lignin as Renewable Raw Material, ChemSusChem 3 (2010) 1227-1235.

[3] J. Zakzeski, P.C.A. Bruijnincx, A.L. Jongerius, B.M. Weckhuysen, The Catalytic Valorization of Lignin for the Production of Renewable Chemicals, Chemical Reviews 110 (2010) 3552-3599.

[4] C. Xu, R.A.D. Arancon, J. Labidi, R. Luque, Lignin depolymerisation strategies: towards valuable chemicals and fuels, Chemical Society Reviews 43 (2014) 7485-7500.

[5] R.J.A. Gosselink, W. Teunissen, J.E.G. van Dam, E. de Jong, G. Gellerstedt, E.L. Scott, J.P.M. Sanders, Lignin depolymerisation in supercritical carbon dioxide/acetone/water fluid for the production of aromatic chemicals, Bioresource Technology 106 (2012) 173-177.

[6] A. Johansson, O. Aaltonen, P. Ylinen, Organosolv pulping - methods and pulp properties, Biomass 13 (1987) 45-65.

[7] Z. Zhang, M.D. Harrison, D.W. Rackemann, W.O.S. Doherty, I.M. O'Hara, Organosolv pretreatment of plant biomass for enhanced enzymatic saccharification, Green Chemistry 18 (2016) 360-381.

[8] R. Rinaldi, R. Jastrzebski, M.T. Clough, J. Ralph, M. Kennema, P.C. Bruijnincx, B.M. Weckhuysen, Paving the Way for Lignin Valorisation: Recent Advances in Bioengineering, Biorefining and Catalysis, Angew Chem Int Ed Eng1 55 (2016) 8164-8215.

[9] W. Schutyser, T. Renders, S. Van den Bosch, S.F. Koelewijn, G.T. Beckham, B.F. Sels, Chemicals from lignin: an interplay of lignocellulose fractionation, depolymerisation, and upgrading, Chemical Society Reviews 47 (2018) 852-908.

[10] M.V. Galkin, J.S. Samec, Lignin Valorization through Catalytic Lignocellulose Fractionation: A Fundamental Platform for the Future Biorefinery, ChemSusChem 9 (2016) 1544-1558.

[11] T. Renders, S. Van den Bosch, S.F. Koelewijn, W. Schutyser, B.F. Sels, Lignin-first biomass fractionation: the advent of active stabilisation strategies, Energy \& Environmental Science 10 (2017) 1551-1557.

[12] B.N. Kuznetsov, V.I. Sharypov, N.G. Beregovtsova, S.V. Baryshnikov, A.V. Pestunov, A.V. Vosmerikov, L. Djakovitch, Thermal conversion of mechanically activated mixtures of aspen wood-zeolite catalysts in a supercritical ethanol, Journal of Analytical and Applied Pyrolysis 132 (2018) 237-244.

[13] B.N. Kuznetsov, N.V. Chesnokov, I.G. Sudakova, N.V. Garyntseva, S.A. Kuznetsova, Y.N. Malyar, V.A. Yakovlev, L. Djakovitch, Green catalytic processing of native and organosolv lignins, Catalysis Today 309 (2018) 18-30.

[14] P. Ferrini, R. Rinaldi, Catalytic biorefining of plant biomass to non-pyrolytic lignin bio-oil and carbohydrates through hydrogen transfer reactions, Angew Chem Int Ed Engl 53 (2014) 8634-8639.

[15] M.V. Galkin, J.S.M. Samec, Selective Route to 2-Propenyl Aryls Directly from Wood by a Tandem Organosolv and Palladium-Catalysed Transfer Hydrogenolysis, ChemSusChem 7 (2014) 2154-2158.

[16] Q. Song, F. Wang, J. Cai, Y. Wang, J. Zhang, W. Yu, J. Xu, Lignin depolymerization (LDP) in alcohol over nickel-based catalysts via a fragmentation-hydrogenolysis process, Energy \& Environmental Science 6 (2013) 994-1007. 
[17] G.S. Macala, T.D. Matson, C.L. Johnson, R.S. Lewis, A.V. Iretskii, P.C. Ford, Hydrogen Transfer from Supercritical Methanol over a Solid Base Catalyst: A Model for Lignin Depolymerization, ChemSusChem 2 (2009) 215-217.

[18] L. Shuai, J. Luterbacher, Organic Solvent Effects in Biomass Conversion Reactions, ChemSusChem 9 (2016) 133-155.

[19] S. Van den Bosch, W. Schutyser, R. Vanholme, T. Driessen, S.F. Koelewijn, T. Renders, B. De Meester, W.J.J. Huijgen, W. Dehaen, C.M. Courtin, B. Lagrain, W. Boerjan, B.F. Sels, Reductive lignocellulose fractionation into soluble lignin-derived phenolic monomers and dimers and processable carbohydrate pulps, Energy \& Environmental Science 8 (2015) 1748-1763.

[20] I. Klein, C. Marcum, H. Kenttämaa, M.M. Abu-Omar, Mechanistic investigation of the $\mathrm{Zn} / \mathrm{Pd} / \mathrm{C}$ catalyzed cleavage and hydrodeoxygenation of lignin, Green Chemistry 18 (2016) 2399-2405.

[21] C. Li, M. Zheng, A. Wang, T. Zhang, One-pot catalytic hydrocracking of raw woody biomass into chemicals over supported carbide catalysts: simultaneous conversion of cellulose, hemicellulose and lignin, Energy \& Environmental Science 5 (2012) 6383-6390.

[22] H. Li, Z. Fang, R.L. Smith Jr, S. Yang, Efficient valorization of biomass to biofuels with bifunctional solid catalytic materials, Progress in Energy and Combustion Science 55 (2016) 98-194.

[23] T. Parsell, S. Yohe, J. Degenstein, T. Jarrell, I. Klein, E. Gencer, B. Hewetson, M. Hurt, J.I. Kim, H. Choudhari, B. Saha, R. Meilan, N. Mosier, F. Ribeiro, W.N. Delgass, C. Chapple, H.I. Kenttämaa, R. Agrawal, M.M. Abu-Omar, A synergistic biorefinery based on catalytic conversion of lignin prior to cellulose starting from lignocellulosic biomass, Green Chemistry 17 (2015) 1492-1499.

[24] N. Yan, C. Zhao, P.J. Dyson, C. Wang, L.T. Liu, Y. Kou, Selective degradation of wood lignin over noble-metal catalysts in a two-step process, ChemSusChem 1 (2008) 626-629.

[25] M.A. Ermakova, D.Y. Ermakov, High-loaded nickel-silica catalysts for hydrogenation, prepared by sol-gel: Route: structure and catalytic behavior, Applied Catalysis A: General 245 (2003) 277-288.

[26] Sharypov V.I., Kuznetsov B.N., Yakovlev V.A., Beregovtsova N.G., Baryshnikov S.V., Djakovitch L., P. C., Composition of Liquid Products of Acetonlignin Conversion Over $\mathrm{NiCu} / \mathrm{SiO} 2$ Catalysts in Supercritical Butanol, Journal of Siberian Federal University. Chemistry 8 (2015) 465-475.

[27] Sharypov V.I., Kusnetsov B.N., Yakovlev V.A., Beregovtsova N.G., B. S.V., Studying the Thermal Conversion of Acetone Lignin in Supercritical Butanol in the Presence of $\mathrm{NiCuMo/SiO} 2$ Catalysts, Catalysis in Industry 9 (2017) 170-179.

[28] A.B. Ayusheev, Taran, O. P., Afinogenova, I. I., Mishchenko, T. I., Shashkov, M. V., Sashkina, K.A., Semeikina, V. S., Parkhomchuk, E. V., Agabekov, V. E., Parmon, V. N. , Depolymerization of Birch-Wood Organosolv Lignin Over Solid Catalysts in Supercritical Ethanol, Journal of Siberian Federal University. Chemistry 9 (2016) 353-370.

[29] A.S. Chikunov, Shashkov, M. V., Pestunov, A. V., Kazachenko, A. S., Mishenko, T. I., Taran, O. P. , Hydrogenolysis of Birch Ethanol-Lignin in Supercritical Over Bifunctional $\mathrm{Ru}$ and Ni Catalysts Bifunctional Supported on Oxidized Carbon., Journal of Siberian Federal University. Chemistry 11 (2018) 131-150.

[30] A.S. Kazachenko, Baryshnikov, S. V., Chudina, A. I., Malyar, Y. N., Sychev, V. V., Taran, O. P. Djakovitch, L., Kuznetsov, B.N., Hydrogenation of abies wood and ethanollignin by molecular hydrogen in supercritical ethanol over bifunctional $\mathrm{Ru} / \mathrm{C}$ catalyst, Chemistry of plant raw materials (2019) 15-26.

[31] V.A. Yakovlev, S.A. Khromova, O.V. Sherstyuk, V.O. Dundich, D.Y. Ermakov, V.M. Novopashina, M.Y. Lebedev, O. Bulavchenko, V.N. Parmon, Development of new catalytic systems for upgraded bio-fuels production from bio-crude-oil and biodiesel, Catalysis Today 144 (2009) 362-366. 
[32] J. Quesada-Medina, F.J. López-Cremades, P. Olivares-Carrillo, Organosolv extraction of lignin from hydrolyzed almond shells and application of the $\delta$-value theory, Bioresource Technology 101 (2010) 8252-8260.

[33] M.V. Alekseeva, M.A. Rekhtina, M.Y. Lebedev, S.G. Zavarukhin, V.V. Kaichev, R.H. Venderbosch, V.A. Yakovlev, Hydrotreatment of 2-Methoxyphenol over High Ni-Loaded Sol-Gel Catalysts: The Influence of Mo on Catalyst Activity and Reaction Pathways, ChemistrySelect 3 (2018) 5153-5164.

[34] O.P. Taran, E.M. Polyanskaya, O.L. Ogorodnikova, C. Descorme, M. Besson, V.N. Parmon, Sibunit-based catalytic materials for the deep oxidation of organic ecotoxicants in aqueous solution: I. Surface properties of the oxidized sibunit samples, Catalysis in Industry 2 (2010) 381-386.

[35] O.P. Taran, C. Descorme, E.M. Polyanskaya, A.B. Ayusheev, M. Besson, V.N. Parmon, Sibunit-based catalytic materials for the deep oxidation of organic ecotoxicants in aqueous solutions. III: Wet air oxidation of phenol over oxidized carbon and $\mathrm{Rr} / \mathrm{C}$ catalysts, Catalysis in Industry 5 (2013) 164-174.

[36] Lavrenov A.V., Basova I.A., Kazakov M.O., Phinevich V.P., Belskaya O.B., Buluchevskii E.A., D. V.K., Catalysts based on anion-modified metal oxides for the production of environmentally friendly components of motor fuels. , Rus. Chem. J. 4 (2007) 75-84.

[37] K. Zhang, H. Li, L.-P. Xiao, B. Wang, R.-C. Sun, G. Song, Sequential utilization of bamboo biomass through reductive catalytic fractionation of lignin, Bioresource technology 285 (2019) 121335.

[38] J.-Y. Kim, S. Oh, H. Hwang, U.-J. Kim, J.W. Choi, Structural features and thermal degradation properties of various lignin macromolecules obtained from poplar wood (Populus albaglandulosa), Polymer Degradation and Stability 98 (2013) 1671-1678.

[39] J.B. Sluiter, R.O. Ruiz, C.J. Scarlata, A.D. Sluiter, D.W. Templeton, Compositional Analysis of Lignocellulosic Feedstocks. 1. Review and Description of Methods, Journal of Agricultural and Food Chemistry 58 (2010) 9043-9053.

[40] E. Sjöström, R. Alén, Analytical Methods in Wood Chemistry, Pulping, and Papermaking, Springer-Verlag, Berlin-Heidelberg, 1999.

[41] S. Wang, W. Gao, H. Li, L.-P. Xiao, R.-C. Sun, G. Song, Selective Fragmentation of Biorefinery Corncob Lignin into p-Hydroxycinnamic Esters with a Supported Zinc Molybdate Catalyst, ChemSusChem 11 (2018) 2114-2123.

[42] M.R. Sturgeon, M.H. O'Brien, P.N. Ciesielski, R. Katahira, J.S. Kruger, S.C. Chmely, J. Hamlin, K. Lawrence, G.B. Hunsinger, T.D. Foust, R.M. Baldwin, M.J. Biddy, G.T. Beckham, Lignin depolymerisation by nickel supported layered-double hydroxide catalysts, Green Chemistry 16 (2014) 824-835.

[43] S. Boonyasuwat, T. Omotoso, D.E. Resasco, S.P. Crossley, Conversion of Guaiacol over Supported Ru Catalysts, Catalysis Letters 143 (2013) 783-791.

[44] T. Omotoso, S. Boonyasuwat, S.P. Crossley, Understanding the role of TiO2 crystal structure on the enhanced activity and stability of $\mathrm{Ru} / \mathrm{TiO} 2$ catalysts for the conversion of lignin-derived oxygenates, Green Chemistry 16 (2014) 645-652. 